\title{
Open Data and Official Language Regimes: An Examination of the Canadian Experience
}

\section{Teresa Scassa*, Niki Singh**}

${ }^{*}$ Canada Research Chair in Information Law, University of Ottawa, Faculty of Law, Ottawa, ON, tscassa@uottawa.ca, 613-562-5800 x 3872, **JD Candidate, University of Ottawa, Faculty of Law, Ottawa, ON,nsing086@uottawa.ca

Abstract: The open data movement is gathering steam globally, and it has the potential to transform relationships between citizens, the private sector and government. To date, little or no attention has been given to the particular challenge of realizing the benefits of open data within an officially bi- or multi-lingual jurisdiction. Using the efforts and obligations of the Canadian federal government as a case study, the authors identify the challenges posed by developing and implementing an open data agenda within an officially bilingual state. Key concerns include (1) whether open data initiatives might be used as a means to outsource some information analysis and information services to an unregulated private sector, thus directly or indirectly avoiding obligations to provide these services in both official languages; and (2) whether the Canadian government's embrace of the innovation agenda of open data leaves minority language communities underserved and under-included in the development and use of open data.

Keywords: open data, open government, bilingualism, multilingualism, official languages.

Acknowledgement: The authors would like to thank the following individuals for their thoughtful comments on earlier drafts of this paper: Graham Fraser, Peter Johnson, François Larocque, Tracey P. Lauriault and Josée Lamothe. We also gratefully acknowledge the support of the Social Sciences and Humanities Research Foundation for the Geothink project, of which this research is a part, and the Canada Research Chairs Programme.

\section{Introduction}

Open data marks a significant transformation in governmental approaches to managing information resources (Roy 2014; Janssen et al 2012). Open data is seen by some as part of a fundamental transformation of the relationship between citizens and the state. Some advocates of open data speak of citizens using open data to "replace functions of government" (O'Reilly 2010, 26) or to put "citizens to work on civic issues" (O'Reilly 2010, 39). Nath $(2011,19)$ suggests that open government in general "empowers citizens to be more actively involved and creative". He 
argues (at 21) that open data is part of a larger "culture of sharing and collaboration that will transform how government operates and ultimately provide better services at a lower cost". Longo $(2011,48)$ notes that open data will allow private sector entrepreneurs "to add value to raw data through the development of citizen-service mobile and web applications".

Given the potential for open data to alter the relationships between citizens, the private sector, and government, this paper considers the impact of such a transformation on a government's obligations to deliver information tools and services to the public in two or more official languages. Official language regimes generally reflect a constitutional arrangement that requires an ongoing commitment of resources and oversight (Desrochers v. Canada 2009). Using the Canadian federal government as a case study, we consider whether open data poses any challenges to the provision of constitutionally mandated bilingual services and how these challenges might be addressed. Key concerns include (1) whether governments might use open data to outsource some information analysis and information services to an unregulated private sector through open data initiatives, thus directly or indirectly avoiding obligations to provide analysis and information tools in official languages; and (2) whether the rush by governments to support the innovation agenda of open data may leave minority language communities both underserved and under-included in the development and use of open data.

The paper begins with a brief overview of the open data movement, its objectives and the manner in which it is being unrolled in Canada. It next examines the constitutional and statutory obligations of the Canadian government with respect to the provision of bilingual services. The relationship of official bilingualism to provincial and municipal open data initiatives is also briefly considered. We next consider the extent to which these obligations are respected in the roll out of federal open data, both in terms of the open data infrastructure and the incentives and support provided for open data uptake and use. The paper concludes with some recommendations for ensuring that open data works to the benefit of both official language communities in Canada.

\section{Open Data: An Overview}

The open data movement is a product both of the rapid technological development that has led to increased computer processing power and increased data storage capacity, and of the rapid diffusion of computing technology across a broad segment of the population. Within this context, the growth of the information economy, and the democratization of information production and dissemination have led to an increased demand for access to government data (Roy 2014; O'Reilly 2010).

Although there are some overlaps between the open data movement and the broader right-toinformation movement (Janssen et al 2012, Kitchin 2014, \& Janssen 2012), the two have always been quite distinct (Janssen 2012). The right-to-information movement has principally been focussed on the goals of transparency and accountability. While these values are present in the open data context as well (Janssen et al 2012; Davies \& Bawa 2012; Open Data Charter 2013), open data has also served an innovation agenda (Ubaldi 2013; Robinson et al 2010). For example, the 
Canadian government has set objectives for itself "to unlock the innovation potential of open data." (Government of Canada 2014a; Open Data Charter 2013). Other stated goals of open data include greater efficiency across levels of government in planning and decision-making as a result of improved internal data sharing (Kitchin 2014), and a broadened input in public policy and analysis (Longo 2011).

Open data generally involves the release of datasets comprised of data collected or generated by government. To qualify as "open" this data must be released to the public in an open, machine readable and non-proprietary format, and under an open licence. The use of open formats is meant to facilitate not only reuse of particular data sets, but also the ability to combine these data sets with data from other sources (Robinson et al 2010). Part of the goal of open data is to harness the economic and informational potential of linking available datasets in innovative ways. (Shadbolt et al 2012; Newman 2010) Open licensing is meant also to ensure easy reuse of the data. (Janssen et al 2012; Ricolfi et al 2011). Licences used by governments for open data include Creative Commons (adopted in both Australia and New Zealand), or some version of a licence specifically tailored for open government data, such as the U.K.'s Open Government Licence (National Archives 2014). This latter licence has been adopted, in modified format, for use at the federal level in Canada (Government of Canada 2013). A key feature of open licences is the relatively unrestricted reuse of the data (some conditions may apply, such as in relation to attribution, for example) (Mehwort 2012). Further, to be truly useful, open data must be easy to find. An important piece of any governmental open data program is a portal through which data sets are made available and are easily searchable (Janssen et al 2012). Open data must also be available to the public at marginal or no cost. Indeed, part of the rhetoric surrounding open data is the argument that since taxpayers have already funded the creation of the data, they are entitled to access it without additional cost (Janssen et al 2012) and without other barriers such as registration requirements (Open Data Charter 2013).

To a large extent, arguments for open data as a solution to the provision of certain types of citizen-facing services are market driven. Johnson \& Robinson $(2014,352)$ suggest that "in many instances, the provision of open data comes with incentives for developers to improve or expand on the service offerings of government." In the transit data context, for example, it has been suggested that opening transit data will lead to the development of a wide variety of different transit apps, and that this will allow consumers to gravitate towards the ones that are the most reliable and that have the most useful features (Rojas 2012; Pessoa et al 2011). It is also argued that different communities will be served by open data better than they would have been served by municipal governments; for example, app developers might develop apps for transit users with particular types of disability or for different minority language communities (Pessoa et al 2011). The extent to which this is the case has yet to be established. In addition, there are claims that open data applications may allow government agencies to lower operating costs by eliminating the need to provide services that will ultimately be offered through the app developer community using government data (Nath 2011).

While much of the rhetoric around open data is about its potential benefits, some scholars offer more critical perspectives. Bates (2012), for example, argues that open data serves a neoliberal 
agenda that moves towards the increasing "marketization" of public services. This may lead to a form of outsourcing of government information services to the private sector (Gurstein 2013). In Canada, the federal open government data initiative has repeatedly emphasized the goal of stimulating innovation. (Government of Canada 2012, Government of Canada 2014a). This explicit innovation agenda risks conflating the public good of open data with private sector commercial interests (Bates 2012). Kitchin $(2014,56)$ also notes the strong private sector interest in "gaining access to a valuable commodity" at marginal or no cost.

Certainly, open data promises to offer more options to citizens in terms of applications for government data - more than what governments would provide - as well as apps that use data from across different governmental silos, creating the kind of tools that no government department or agency would have the mandate or incentive to create. Further, by making the data freely available, the number of different applications is limited only by the resources and creativity of the user community - the cost of access to the data is no longer a barrier to activity in this field. Nevertheless, it remains to be seen whether open data also leads, in some cases, to governments getting out of the business of providing tools and information services beyond the provision of the raw data that can be used by the private sector for these purposes (Nath 2011). As Johnson and Robinson observe $(2014,352)$, the open data phenomenon may be part of a "shifting role of government from direct service provider to citizens, to the more libertarian imagining of government as a platform, limited to maintaining basic infrastructure while the private sector assumes the role of primary service provider to citizens."

\section{Open Data: From Local to National}

The most useful open data at the level of citizen services and citizen access is that which most closely impacts on the daily activities of individuals. Thus it is to be expected that municipal open data will feature in most apps with a high popular uptake. This has been the case, for example, with municipal transit data (McHugh 2013, Rojas 2012), but also with other types of apps. Recent Canadian examples include apps which combine information on water resources and weather data for those interested in fishing (iFishOntario), apps that correlate rental unit information with bylaw infraction data (Vancouver RentalDog), and apps using open data that allow diners to view restaurant safety inspections (DineSafe Toronto), to give a few examples. Nevertheless, there are a broad variety of apps that can be developed using federal-level data. Most of those currently showcased on the federal open government site are provided by government (and many are not true apps, but rather simply searchable databases). However, there are already a few publicly available apps created by developers that make use of federal data. Some of these relate to weather (Radar Map, Weather Watchers), the analysis of public data relating to contracting (ContractsinCanada.ca), or government expenditures (Public Accounts of Canada).

The focus of this paper is on open data at the federal level in Canada because of the Canadian government's express bilingualism obligations. However, because of the closer link between municipal data and the daily lives of individuals, we acknowledge that the issues we raise might be even more acute in the context of an officially bi- or multi-lingual province or municipality. The 
problem would also be very real in a province like Ontario, where, although there is no constitutional requirement of bilingualism, there is nevertheless a legislative commitment to providing French language services (French Language Services Act). Nevertheless, the issues remain important at the federal level both in general, and in relation to the broader leadership role of the federal government in Canada around open data.

\section{Open Data in Canada}

The federal government's embrace of the open data agenda comes through both its membership in the Open Government Partnership (OGP), an international multi-stakeholder organization aimed at increasing the transparency and accountability of governments worldwide, and the signing of the Open Data Charter at the G8 leaders' meeting in 2013 (Open Data Charter 2013). Nevertheless, the government's open data initiatives began somewhat earlier. High-value federal government geospatial datasets were among the Canadian government's early experiments with open data. The government established an entity called Geoconnections, which is self-described as a "national partnership initiative led by Natural Resources Canada designed to facilitate access to and use of geospatial information in Canada through the development, integration and use of the Canadian Geospatial Data Infrastructure (CGDI)" (Natural Resources Canada 2014). Like geospatial data infrastructures in other countries, the CGDI has sought to establish standards, template licences, and other tools that would facilitate greater access to and use of geospatial information in Canada (Lauriault and Kitchin 2014). While the federal government is a source of much geospatial data, provincial and municipal governments are also important sources - a key objective of the work of Geoconnections was to facilitate the sharing and use of such data across levels of government and by the private sector. Standard formats and interoperable licences were important to meet these goals. Geoconnections was involved in developing these resources. It was also involved in creating its own data portal (Geoconnections). The work of Geoconnections laid important foundations for the federal government's open data initiative. Essentially, this latter initiative followed many of the same principles and practices but on a larger scale. When the federal open data portal launched in 2011, the vast majority of available datasets were geospatial - reflecting the significant strides already made in this area.

Since its initial commitment to the Open Government Partnership in 2012, the federal government has released two action plans on open government, covering what it characterizes as its three core commitments: open information, open data, and open dialogue (Government of Canada 2012; Government of Canada 2014a). It is probably fair to say that of its open government commitments, it is the open data component that has received the most attention and resources (Francoli 2013). The government's Action Plans have stressed the innovation dimensions of open data. For example, the first Action Plan (Government of Canada 2012) defined its "open data" stream as "making raw data available in machine-readable formats to citizens, governments, notfor-profit and private sector organizations to leverage it in innovative and value-added ways." In the Action Plan 2.0, the government refers to its goals in this area as being to "unlock the innovation potential of open data" (Government of Canada 2014a). In addition, as will be discussed below, resources committed to supporting the uptake and use of open data also serve an 
innovation agenda. Although the government emphasis has been on innovation, open data can also support civil society goals such as transparency and accountability. In the context of official language communities, an emphasis on innovation rather than on civil society uptake and use may shift resources away from measures to assist, for example, with the development of open data literacy in minority language communities and with the skills enhancement necessary to allow these communities to make use of open data for civil society, civic engagement, and advocacy purposes.

Although the federal Open Data Portal was initially populated by geospatial data sets already made available through the work of Geoconnections, the number and variety of datasets has been increasing steadily, with contributions of data from a range of government agencies and departments. In its recently released Action Plan on Open Government 2.0, the federal government has indicated a strong commitment to work with governments at other levels in Canada not only to increase the availability of open data from all levels of government, but also to increase the harmonization of standards and licensing in order to ensure greater interoperability, and thus greater uptake and use of the data (Government of Canada 2014a).

Open data has no value if it is not used (Janssen et al 2012). Indeed, while the many promises of open data around innovation and economic development cannot be achieved without the legal and technological framework described earlier, they will also be difficult to realize if the public is unaware of the data resources, unsure of how to exploit their potential, or lacking the necessary technical skills to make use of them. Thus, it is significant to note the additional commitments in the federal government's Action Plan 2.0 (Government of Canada 2014a), that are aimed at encouraging the use of open data. These are: open data hackathons, the open data institute, and data literacy initiatives. These are discussed in Part 4.2, below.

\section{Canada's Bilingualism Obligations}

Canada is a federal state consisting of 10 provinces and three territories. Under its constitution, the country is officially bilingual at the federal level. New Brunswick is the only province to be officially bilingual under the Constitution. The official language of the province of Quebec is French. Inuit, English and French are the official languages of the territory of Nunavut. The Northwest Territories have 11 official languages, including English and French. While Yukon Territory recognizes a number of aboriginal languages, government and court services are available only in English and French. All other provinces operate in English. While the majority of Canadian francophones live in Quebec, there are substantial French-speaking minority language communities elsewhere in Canada. According to Statistics Canada, over a million residents of Canada outside of Quebec indicate that French is their mother tongue (Statistics Canada 2014). Three quarters of that number live in either Ontario or New Brunswick (Statistics Canada 2014). Nevertheless, there are French-language communities in most of the other Canadian provinces.

Canada's official French and English bilingual status is entrenched in the Canadian Charter of Rights and Freedoms (1982). Under subsection 16(1) of the Charter, the two languages are equal 
with respect to their use in "all of the institutions of the Parliament and the government of Canada." Further, under subsection 20(1) of the Charter, the right of any member of the Canadian public to communicate with and to receive services from any institution of the Parliament or government of Canada is guaranteed, although the scope of such rights may be limited with respect to government offices located in regions of the country where there is not a significant demand for services in one or the other of the official languages.

In addition to these constitutional guarantees, the federal Official Languages Act provides the framework for implementing these rights and establishes an oversight mechanism through an ombud's office to ensure that the commitments are met. The purposes of the Official Languages Act, as set out in section 2, include to

ensure respect for English and French as the official languages of Canada and ensure equality of status and equal rights and privileges as to their use in all federal institutions, in particular with respect to ... communicating with or providing services to the public and in carrying out the work of federal institutions [and to] support the development of English and French linguistic minority communities and generally advance the equality of status and use of the English and French languages within Canadian society.

Beyond these broad obligations, there are other more specific ones. One of these includes the obligation in s. 25 of the Official Languages Act to ensure that government services that are contracted out meet the bilingualism requirements that would otherwise be imposed on the government. Open data, of course, does not involve the express contracting out of government services in the sense that no particular services are specifically commissioned, paid for or delivered. An important question, however, is the extent to which open data initiatives within a neoliberal frame actually result in the offloading of certain government information services to developers in the private sector.

To a large extent, it is through Treasury Board policies that individual government agencies and departments are guided in meeting their obligations under the Official Languages Act. For example, the Directive on Official Languages for Communications and Services (2012) provides specific guidelines on how bilingualism should be incorporated in federal government communications. This Directive requires that both official languages be used in both online and web applications (s. 6.6), that they should be treated equally (s. 6.6.3.1), and be of equal quality (s. 6.6.4.1). Under the Communications Policy of the Government of Canada (2012, s. 18) it is also the responsibility of federal government institutions to ensure that their electronic communications conform to official language policies. In addition, there are web-specific bilingual requirements of government communications. Domain names and splash pages are required to be bilingual (Standard on Web Usability 2013). If information on the web is only available in one language, a notice must be served next to a hyperlink, informing the user of unilingual availability (i.e., French only, anglais seulement) (s. 4). Government social media accounts must also be available in both official languages (Guideline on Official Use of Social Media). Media files that are inherently unilingual should have subtitles or transcriptions in order to comply with official language requirements (Guideline on Official Use of Social Media). There are very few exceptions to the 
bilingual requirements at the federal government level. These exceptions only exist if the institutional body falls outside the scope of the "nature of the office" and "significant demand" provisions in the Charter.

\subsection{General Compliance with Bilingualism Requirements}

Compliance with federal bilingualism requirements seems to be largely in place with respect to open government data in general terms. Policy documents, action plans, and consultations with respect to open government are prepared and disseminated in both official languages. The Open Government Licence is bilingual. While this is required under the Official Languages Act for a federal government document of this kind, it is also an important feature if the licence is to be adopted and used by other levels of government across the country. The open data portal is also bilingual, and data sets are searchable through this portal in both official languages.

While much of the basic open data infrastructure is bilingual, it is worth noting that the Application Programming Interface (API) provided for developer use and its supporting documentation are in English only. The API is a tool that allows developers to make automated calls for data to government databases. As this open source software is not developed by the federal government, no bilingualism requirements apply to it. Further, its development is not necessarily commissioned by government. The use of open source software and associated resources is highly encouraged in the open data context, and it is a cost-effective means to implement open data (Daffara \& Gonzalez-Barahona 2010). Professional software developers are no doubt well-versed in using English-only software tools. Nevertheless, it is worth considering whether a unilingual English programming environment may pose an additional barrier to use of open government data within majority or minority French-language communities.

A majority of datasets available through the open data portal are available in both French and English, with supporting documentation available in both languages. While a few datasets may be available in English only (e.g., Air Quality Health Index Forecast), supporting documentation may still be available in both official languages. A listing of available apps using federal government data contains a significant number of information tools developed by the federal government itself, in both official languages. However, the majority of these are not new apps per se, but rather are pre-existing government information tools, such as online searchable databases. Among new, citizen-developed apps on the federal open data site, four (at the time of writing) were available in both French and English.

Overall, care seems to have been taken in the bilingual design and unrolling of the open data portal, licences, and documentation. However, while there are still very few published apps that make use of federal open data (other than those provided by the government itself), only a small minority of these are available in a French language version. There is reason to be concerned, therefore, about the next point in our discussion, which is the implementation of the open data agenda. 


\subsection{Implementing the Open Data Agenda}

The manner in which government support is allocated for different types of initiatives falls within the mandate of the Official Languages Commissioner. Thus, for example, there is a responsibility to ensure that funding to support creative or cultural initiatives is made available within both official language communities. (Commissioner of Official Languages, 2014) Further, the Supreme Court of Canada acknowledges the possibility that substantive equality in language services by government may require more than the provision of identical services to both linguistic communities (DesRochers v. Canada 2009). The Official Languages Act also commits the government to "enhancing the vitality of the English and French linguistic minority communities in Canada and supporting and assisting their development." (Official Languages Act, s. 41(1). Section 41(3) of the Official Language Act places a clear onus on federal institutions to take positive steps to meet this commitment. As government begins to promote its open data initiatives and to encourage the update and use of open government data, it is therefore incumbent on government to ensure that it does so in a way that supports the development and use of open data by both francophones and anglophones.

In order to maximize the uptake and use of open data - and thus to benefit from its potential in stimulating innovation and economic development, it is essential to ensure that the public and the developer community are aware of the existence of the data, have incentives to make use of it, and have the necessary skills (Janssen et al 2012, 265; Gurstein 2011). The federal government itself recognizes this in its Action Plan on Open Government 2.0 (Government of Canada 2014), where it makes specific commitments to increasing data literacy, providing incentives to use federal open data, and providing infrastructure to support development using open data. A key question in considering the government's official bilingualism commitments is the extent to which these outreach and development initiatives meet and serve the needs of both official language communities in Canada.

\subsubsection{Hackathons}

It has become relatively common practice for governments moving toward open data to provide a variety of tools and incentives beyond portals and open licences in order to support and encourage developers. One widely used tool for encouraging and incentivizing the use of open data is the hackathon (Johnson \& Robinson 2014; Roy 2014; Demeyer et al 2012). Hackathons are full day or weekend events at which developers are challenged to come up with useful new apps based on open government data. In some cases, the organizers will specify a particular theme or set of issues to be addressed; in other cases they may provide new, previously unreleased data sets (Johnson \& Robinson 2014; Roy 2014). Hackathons typically feature a cash prize for the most useful or innovative app (Demeyer et al, 2012).

Johnson and Robinson have raised the issue of whether civic hackathons are a form of public procurement; in most cases, the resources and encouragement provided by government - and even the direction - are not equivalent to a more focussed request for proposals used in the outsourcing of the development of software for government purposes (Porway 2013). Thus they 
are not procurement in any traditional sense. Nevertheless, such activities aim to engage developers more broadly in discovering and using open government data and in developing new apps that make use of this data for a variety of purposes. To the extent that the private sector becomes engaged in developing apps that make use of government data to serve the public, the government's role as a provider of information and services will begin to shift.

If hackathons are to be used by the federal government to unroll and promote its open data agenda and to encourage the development of apps that make use of government data for the better service of Canadians, it is important to consider the extent to which the goals of official bilingualism are met in this sphere. The federal government already has particular guidelines about how it should handle bilingual requirements during partnerships and sponsorship initiatives. This would include events like hackathons. According to the government rules, all advertising done by the federal government must be bilingual (Communications Policy 2012, s. 23). Beyond that, the Communications Policy of the Government of Canada (2012, s. 24) states that in partnering or entering into collaborative arrangements, government institutions must "analyse the public environment and take account of the views, concerns and language preferences of citizens and stakeholders before entering into an agreement".

The federal government has sponsored two major hackathons to encourage the use of federal open data. The first Canadian Open Data Experience (CODE) hackathon took place in March of 2014. Although the event was based in Toronto, it allowed for virtual participation from anywhere in Canada. CODE 2014 featured a \$25,000 prize for the best app, and, according to the federal government, had over 900 participants (Government of Canada 2014d). The second CODE hackathon took place in February 2015. This event also allowed virtual participation, but it had three geographic hubs: in Toronto, Vancouver and Montreal. It featured a top prize of $\$ 15,000$ and several smaller prizes in different categories. It had over 1300 participants. The Government of Canada has been a top-level sponsor of CODE, although it is not the organizer. The CODE events were hosted by XMG, a Canadian online gaming company. In 2014, the winning app, named newRoots combined data sets relating to a variety of government services along with demographic data. The result was a tool designed to allow new immigrants to Canada to match their own skills and interests with particular neighborhoods which have features that might be more conducive to their successful integration. Johnson and Robinson $(2012,351)$ describe this app as aiming "to package and deliver government data to meet a perceived need currently unfilled by existing government services." The app, which functioned only in English, did not replace or duplicate existing government services; indeed, what it provided was something more akin to a value-added service provided by the private sector. The 2015 winning app was called Career Path, and used employment and job market statistics to predict employment opportunities (CODE 2015).

The CODE websites are bilingual, and it was possible to register for the contest in either French or English and to submit an app in either language. In spite of the bilingual dimensions of CODE it has produced apps that are for the most part, English only (Government of Canada 2014b; CODE 2015). Of course, the nature of the competition requires a 48 hour turnaround, so the language of an app is in part determined by the language of the programmers, and there is nothing to prevent later app development or commercialization to take into account French language functionality. 
Government documentation shows that there was considerable participation from coders in the majority French-speaking province of Quebec, although participation was heaviest in Ontario. (Government of Canada 2014d) Apart from the bilingual website, CODE 2015 event communications were predominantly in English. Tweets from the official hashtag of the event were almost exclusively in English. While the CODE host was a private sector company not bound by official languages requirement, the Government of Canada had identified CODE as part of its Action Plan on Open Government, and was a top sponsor of the hackathons. In this light, the unilingual communications appear problematic. It is also worth noting that several tweets regarding CODE from the Treasury Board Secretariat were in English only (CODE 2015). The Minister responsible for the Treasury Board Secretariat, Tony Clement, has publicly clashed with the Official Languages Commissioner on the issue of whether his tweets properly balance French and English (Fekete 2014). However, the unilingual CODE tweets were from the Treasury Board Secretariat and not from the Minister personally, and do raise issues of compliance with government policy.

Issues raised by these hackathons include whether the resources put into CODE sufficiently reached or attracted participation not just from French-language coders in Quebec, but from Francophone minority communities outside of Quebec. To the extent that they did not, a further question, which is related to the issue of digital literacy, discussed below, is whether there exists sufficient digital literacy in French-speaking communities outside of Quebec to engender participation, and if not, what measures are being taken to address the specific needs of those communities.

\subsubsection{Canadian Open Data Institute}

In its 2014 Budget, the federal government announced the creation and funding of an open data institute with a mandate to: 1) develop and promote the use of common data standards across Canada; 2) stimulate the development of apps through appathons; and 3) to encourage the use of open data generally (Government of Canada 2014c). In its Action Plan on Open Government 2.0, the federal government provided additional details, including a new name for the initiative - the Open Data Exchange (ODX) (Government of Canada 2014a). According to the government,

ODX will develop industry standards for open data, build a national marketplace where commercialization of open data can flourish, and support a pan-Canadian open data innovation community that will help incubate the next generation of data-driven companies (Government of Canada 2014a).

The mandate of ODX appears to be heavily oriented towards an innovation agenda.

ODX is to be a public-private-partnership between the federal government, Communitech, two software companies (Open Text and Desire2Learn) and the University of Waterloo. It will be funded by contributions of $\$ 3$ million from private sector partners matched by a further $\$ 3$ million from the federal government, and will be based in the Waterloo region of Ontario. There is no information available on the extent to which ODX will have either the mandate or the resources to support innovation and commercialization in the French language. 


\subsubsection{Digital Literacy}

In order to fulfill the many promises of open data, a substantial degree of data literacy will be required across the general population. Digital literacy is a term used by the federal government in its Open Government Action Plan 2.0 to refer to the "essential skills needed to access, understand and use digital information and new technologies" (Government of Canada 2014a). In the context of open data, this would include not only the basic skills needed to use technological tools, but also some ability to understand the metadata that accompanies open data sets, to understand the scope and limitations of the data, and to be able to both interpret and use the data effectively. Robinson et al (2010 at 89 ) urge us to imagine a context "in which citizens themselves interact directly with data without needing an intermediary." Given the current state of digital and data literacy, this may be a rather ambitious goal. Indeed, Gurstein (2011) has cautioned that there is a sharp distinction between the opportunities for reuse of digital data and the ability to realize these opportunities. He argues (Gurstein 2011 at 2) that "'open data' empowers those with access to the basic infrastructure and the background knowledge and skills to make use of the data for specific ends." Clearly, some level of digital literacy will be essential to assist Canadians in becoming aware of available data and of how the data might be relevant or useful to them, to their businesses, or to their civil society activities. Digital literacy can also assist in helping ordinary Canadians to critically examine data that is presented to them by those who make use of open data to create apps, visualizations, reports, or other information tools using open data. Digital literacy challenges are quite significant. In this respect, it is important to note that the federal government, in its Action Plan on Open Government 2.0 has made certain commitments around digital literacy (Government of Canada 2014a). In general terms, in its Action Plan 2.0 (Government of Canada 2014a) the federal government proposes to support "the development of tools, training resources, and other initiatives to help Canadians acquire the essential skills needed to access, understand, and use digital information and new technologies." Its more specific goals are to carry out research, to develop a picture of Canadians' digital literacy across regions and demographic groups, to develop skills through training and online resources, and to fund specific initiatives to improve digital literacy in specifically targeted regions or demographics or for certain employment sectors (Government of Canada, 2014a).

The government's commitments to digital literacy do not address language specifically, although it is to be expected that any measures rolled out through online tools and training materials will be in both French and English. Nevertheless, it might be useful to have specific resources directed towards assessing specific digital literacy issues facing minority francophone communities across Canada. These issues may be exacerbated by the reality that many software tools and programming instructions may be available only in English.

\section{Conclusions}

A review of the Canadian federal open data programme to date shows a formal compliance with bilingualism requirements. The documentation related to open data, including consultation documents, action plans and reports, is all available in French and English. Services such as the 
open data portal are also available in both official languages. What is less clear is whether the strategies to create opportunities and incentives to make use of open data are available on a substantively equal basis, particularly as concerns minority French-language speaking communities outside of Quebec. This may be due, in part, to the strong focus on the innovation agenda as it pertains to open data. There may simply be less interest on the part of government to invest in the development of skills for civil society uptake and use of open data.

Federally-sponsored hackathons enable virtual participation from anywhere in the country. Nevertheless, there is no obvious outreach to minority language communities. To the extent that open data is meant to engage citizens, and to facilitate the development of useful apps employing government data, there is reason to be concerned if the output of the CODE events, and the development more generally of apps based on federal data, continue to be dominated by apps that are available in English only. French-language communication about these events could certainly be improved. While recognizing the freedom of participants to develop apps in the language of their choice, more attention must be paid to encouraging greater participation in the development of apps that make use of government information by and for both linguistic communities.

Because the Open Data Exchange is only in its infancy, it is difficult to assess the extent to which this institute or its activities will serve the needs of minority French-language communities, but the early days of this initiative suggest that funds are concentrated on commercial innovation and that there is no mandate for outreach to French-language communities. Beyond this, there is nothing in the public documentation relating to the government's open data initiatives that addresses the development of the skills and resources needed to ensure that francophone communities can take equal advantage of the benefits of open data. Given the claims that open data will lead to greater citizen engagement, enhanced transparency and accountability, and the stimulation of economic activity, some strategy to ensure that government offers substantively equal opportunities to both language communities is required.

It has been suggested by some that open data will shift the responsibility for providing tools and services based on government information to the private sector and away from the public sector. While this could be of considerable concern in an officially bi- or multi-lingual jurisdiction, there is presently insufficient evidence to establish that this is the practical result of open data initiatives. In Canada, the use of open government data for novel, citizen-facing apps has been relatively insignificant to date, especially in relation to federal data. Nevertheless, this remains an issue to watch. In a context where the government is expending resources to encourage the uptake and use of open data in these ways, the allocation of these resources should explicitly identify and address the needs of both official language communities in Canada.

\section{References}

Bates, Jo. 2012. "“This is what modern deregulation looks like”: Co-optation and contestation in the shaping of the UK's Open Government Data Initiative", Journal of Community Informatics, 8:2, online: http:/ / ci-journal.net/index.php/ciej/article/view/845/916 
Canadian Charter of Rights and Freedoms, The Constitution Act, 1982, being Schedule B to the Canada Act 1982 (UK), 1982, c 11

CODE 2015. Online: https:/ / www.canadianopendataexperience.ca/

Commissioner of Official Languages, Canada. 2014. Annual Report 2013-2014. Minister of Public Works and Government Services Canada. Online: http://www.officiallanguages.gc.ca/sites/default/files/annual_report_1314.pdf.

Communications Policy of the Government of Canada, April 1, 2012. Government of Canada: http://www.tbs-sct.gc.ca/ pol/doc-eng.aspx?section=text\&id=12316.

Constitution Act, 1867 (UK), 30 \& 31 Victoria, c 3

ContractsinCanada.ca. Online: http://open.canada.ca/en/apps/contractsincanadaca

Daffara, Carlo and Gonzalez-Barahona, Jesus M. 2010. “Open source software for open government agencies". In Open government, Edited by: Lathrop, D. and Ruma, L. 345-361. Sebastopol, CA: O'Reilly Media.

Davies, Tim \& Zainab Ashraf Bawa. 2012. "The Promises and Perils of Open Government Data". Journal of Community Informatics, 8:2. Online: http://ci-journal.net/index.php/ciej/article/view/929/955.

Demeyer, Tom, Frank Kresin, Carine van Oosteren, Katalin Gallyas. 2012. "Field Note Apps for Amsterdam". Journal of Community Informatics 8:2, online: http://cijournal.net/index.php/ciej/article/view/850/906.

Desrochers v. Canada (Industry), 2009 SCC 8.

DineSafe Toronto, https://itunes.apple.com/us/app/dinesafe-toronto-restaurant/id602002198?ls=1\&mt=8

Directive on Official Languages for Communications and Services, November 19, 2012. Treasury Board of Canada: https:/ / www.tbs-sct.gc.ca/pol/doc-eng.aspx?id=26164\&section=text.

Fekete, Jason. 2014. "Treasury Board President Tony Clement vows to quit Twitter if language police try to 'overlord' him." $\quad$ August 22. National Post. Online: http:/ / news.nationalpost.com/2014/08/22/treasury-board-president-tony-clement-vows-to-quittwitter-if-language-police-try-to-overlord-him/.

Francoli, Mary. 2013. Independent Reporting Mechanism: Canada: Progress Report 2012-13, Open Government Partnership, online: http://www.opengovpartnership.org/sites/default/files/Canada_final_2012_Eng.pdf.

French Language Services Act, RSO 1990, Chapter F-32.

Geoconnections. infrastructure/8906

http://www.nrcan.gc.ca/earth-sciences/geomatics/canadas-spatial-data-

Government of Canada. 2014a. Canada's Action Plan on Open Government, 2014-2016. Online: http://open.canada.ca/en/content/canadas-action-plan-open-government-2014-16. 
Government of Canada. 2014b. Apps Gallery. Online: http://open.canada.ca/en/apps?f[0]=im_field_departments\%3A700.

Government of Canada. 2014c. Idea Details: Open Data Institute (ODI). Online: http://open.canada.ca/en/Open_Data_Institute_\%28ODI\%29.

Government of Canada. 2014d. Canadian Open Data Experience \{CODE\} 2014 Event. Online: http://open.canada.ca/en/code-2014-event.

Government of Canada. 2013. Open Government Licence - Canada, Version 2.0. Online: http://open.canada.ca/en/open-government-licence-canada.

Government of Canada 2012, Canada's Action Plan on Open Government 2012-2014, online: http://open.canada.ca/en/canadas-action-plan-open-government.

Guideline on Official Use of Social Media. Treasury Board of Canada: http://www.tbs-sct.gc.ca/pol/doceng.aspx?id=27517\&section $=$ text.

Gurstein, Michael. 2013. "Should "Open Government Data" be a product or a service (and why does it matter?)", Gurstein's Community Informatics, 3 February. Online: https://gurstein.wordpress.com/2013/02/03/is-open-government-data-a-product-or-a-service-andwhy-does-it-matter/.

Gurstein, Michael. 2011. "Open data: Empowering the empowered or effective data use for everyone?", First Monday,16:2, online: http:/ / firstmonday.org/article/view/3316/2764

iFishOntario, online: http://www.ifishontario.com.

Janssen, Katleen. 2012. "Open Government Data and the Right to Information: Opportunities and Obstacles", Journal of Community Informatics, 8:2, online: http://cijournal.net/index.php/ciej/article/view/952/954.

Janssen, Marijn, Yannis Charalabidis \& Anneke Zuiderwijk. 2012. Information Systems Management, 29:4, 258-268, DOI 10.1080/10580530.2012.716740

Johnson, Peter \& Pamela Robinson. 2014. "Civic Hackathons: Innovation, Procurement or Civic Engagement?", Review of Policy Research, 31:4, 349-357.

Kitchin, Rob. 2014. The Data Revolution: Big Data, Open Data, Data Infrastructures \& Their Consequences. (London: Sage), 222pp.

Lauriault, Tracey P. and Rob Kitchin, 2014, A genealogy of data assemblages: tracing the geospatial open access and open data movements in Canada, AAG Session 4204, Data-based living: peopling and placing ‘big data, Tampa, Florida, April 112014

Longo, Justin. 2011. “\#OpenData: Digital-Era Governance Thoroughbred or New Public Management Trojan Horse”, Public Policy \& Governance Review 2:2, 38-51.

McHugh, Bibiana. 2013. "Pioneering Open Data Standards: The GTFS Story", in Brett Goldstein and Lauren Dyson, eds., Beyond Transparency: Open Data and the Future of Civic Innovation, San Francisco: Code for America Press, 125-135. 
Mehwort, Kent. 2012. Creative Commons Licences: Options for Canadian Open Data Providers. Available at: https://www.cippic.ca/sites/default/files/Creative\%20Commons\%20Licenses\%20\%20Options\%20for\%20Canadian\%20Open\%20Data\%20Providers.pdf.

Nath, Jay. 2011. "Reimagining Government in the Digital Age”, Wiley Periodicals. DOI: 10.1002/ncr.20070, 10-23.

National Archives, U.K. 2014. Open Government Licence for Public Sector Information, Version 3.0. Online: http://www.nationalarchives.gov.uk/doc/open-government-licence/version/3/.

Natural Resources Canada. 2014. Geoconnections. Online: http://www.nrcan.gc.ca/earthsciences/geomatics/canadas-spatial-data-infrastructure/8906.

Newman, Daniel. 2010. "Case Study: MAPLight.org", in Open government, Edited by: Lathrop, D. and Ruma, L. 223-232. Sebastopol, CA: O'Reilly Media.

Official Languages Act, RSC 1985, c 31 (4th Supp)

Open Data Charter. 2013. http://www.international.gc.ca/g8/open_data_chartercharte_du_g8_sur_les_donnees_ouvertes.aspx?lang=eng.

Open Government Partnership. Online: http://www.opengovpartnership.org/.

O'Reilly, Tim. 2010. "Government as a Platform", in D. Lathrop and L. Ruma, eds., Open Government: Collaboration, Transparency, and Participation in Practice. (Sebastopol, CA: O’Reilly), 11-39.

Pessoa, Lauren, Landon Reed, Jacob Tzegaegbe, James Wong \& Ben Yan. 2011. “Enabling Transit Solutions: A Case for Open Data", Georgia Institute of Technology, Fall 2011

Porway, Jake. 2013. "You Can't Just Hack Your Way to Social Change", March 7. Harvard Business Review Online. Online: https://hbr.org/2013/03/you-cant-just-hack-your-way-to/.

Public Accounts of Canada 2009-2012. Online: http://open.canada.ca/en/apps/public-accounts-canada2009-2012).

Radar Map. Online : http://open.canada.ca/en/apps/radar-map-windows-store

Ricolfi, Marco; van Eechoud, Mireille; Morando, Federico; Tsiavos, Prodromos and Ferrao, Luis. 2011. LAPSI Position Paper No. 3: The "Licensing" of Public Sector Information, http://www.lapsiproject.eu/lapsifiles/lapsi_licensing_paper.pdf.

Robinson, David G., Harlan Yu, and Edward W. Felten. 2010. “Enabling Innovation for Civic Engagement”, in D. Lathrop and L. Ruma, eds., Open Government: Collaboration, Transparency, and Participation in Practice. (Sebastopol, CA: O'Reilly), 83-90.

Rojas, Francisca M. 2012. Transit Transparency: Effective Disclosure Through Open Data. Ash Center for Democratic Governance and Innovation. Available at: http://www.transparencypolicy.net/assets/FINAL_UTC_TransitTransparency_8\%2028\%202012.pdf, at 22.

Roy, Jeffrey "Open Data and Open Governance in Canada: A Critical Examination of New Opportunities and Old Tensions", Future Internet 2014, 6(3), 414-432; doi:10.3390/fi6030414 
Shadbolt, Nigel, O'Hara, Kieron, Berners-Lee, Tim, Gibbins, Nicholas, Glaser, Hugh, Hall, Wendy and schraefel, m.c. 2012. "Linked open government data: lessons from Data.gov.uk. IEEE Intelligent Systems", Spring Issue, 27:3,16-24. (doi:10.1109/MIS.2012.23).

Standard on Web Usability, March 31, 2013. Treasury Board of Canada: http://www.tbs-sct.gc.ca/pol/doceng.aspx?section=text\&id $=24227$

Statistics Canada. 2014. French and the Francophonie in Canada: Language, 2011 Census of Population. Online: http://www12.statcan.gc.ca/census-recensement/2011/as-sa/98-314-x/98-314-x2011003_1eng.pdf.

Ubaldi, Barbara (2013), “Open Government Data: Towards Empirical Analysis of Open Government Data Initiatives", OECD Working Papers on Public Governance, No. 22, OECD Publishing. http://dx.doi.org/10.1787/5k46bj4f03s7-en

Vancouver RentalDog. Online: http:/ / www.rentaldog.net

Weather Watchers. Online: http://open.canada.ca/en/apps/weather-watchers.

\section{About the Authors}

\section{Teresa Scassa}

Teresa Scassa is the Canada Research Chair in Information Law at the University of Ottawa, Faculty of Law, Common Section.

\section{Niki Singh}

Niki Singh is a research assistant and J.D. candidate at the University of Ottawa, Faculty of Law. 